\title{
Técnicas anestésicas em odontologia: o que o profissional precisa saber?
}

Anesthetic techniques in dentistry: what does the professional need to know?

\section{Beatriz Paraná Silva Costa}

Aluna da Faculdade de Odontologia da Universidade Federal Fluminense UFF, Niterói/RJ.

\section{Suelen Cristina Sartoretto Lorenzzi}

Pós - doutora em Odontologia da Universidade Federal Fluminense - UFF, Niterói/RJ.

\section{Marcelo José Pinheiro Guedes de Uzeda}

Professor de Cirurgia Oral Menor e Anestesiologia da Faculdade de

Odontologia da Universidade Federal Fluminense - UFF, Niterói/RJ.

\section{Rafael Seabra Louro}

Professor de Cirurgia Oral Menor e Anestesiologia da Faculdade de Odontologia da Universidade Federal Fluminense - UFF, Niterói/RJ.

\section{Mônica Diuana Calasans Maia}

Professora de Cirurgia Oral Menor e Anestesiologia da Faculdade de Odontologia da Universidade Federal Fluminense - UFF, Niterói/RJ.

\section{Rodrigo Figueiredo de Brito Resende}

Professor de Cirurgia Oral Menor e Anestesiologia da Faculdade de Odontologia da Universidade Federal Fluminense - UFF, Niterói/RJ.

Instituição na qual o trabalho foi realizado: Faculdade de Odontologia da Universidade Federal Fluminense Niterói/RJ.

Categoria: Revisão de literatura

\section{Informações do autor principal:}

Nome: Rodrigo Figueiredo de Brito Resende Endereço: Rua Mário Santos Braga, 28, Faculdade de Odontologia. E-mail: resende.r@hotmail.com 


\title{
RESUMO
}

O uso de soluções e técnicas anestésicas são recursos utilizados para o controle local da dor. Esses artifícios sofreram mudanças nas substâncias utilizadas, bem como nas técnicas de acordo com o passar do tempo. A maioria das evoluções teve como objetivo a melhoria do bem-estar do paciente durante as consultas odontológicas. Diante da variedade de técnicas e de bibliografias, possivelmente há diversas dúvidas, onde a maioria deve abranger a escolha do melhor método e das regiões anestesiadas. A partir disso, o objetivo deste trabalho é facilitar a visualização das técnicas anestésicas, bem como auxiliar o atendimento do profissional e seu paciente, otimizando-o.

Palavras - Chave: Odontologia; Técnicas anestésicas; Cirurgia oral.

\begin{abstract}
The use of anesthetic solutions and techniques, the resources used do not control the local website. These are suffered artifacts that were used, as settlement techniques or passing the time. Most developments aim to improve the patient's well-being during dental consultations. By various techniques and bibliographies, it is possible to ask several questions, on the other hand, from the beginning to the blocking of the anesthetized regions method. Based on this, or the objective of this work, it is to facilitate the visualization of anesthetic techniques, such as assisting or assisting professional and patient, optimizing it.
\end{abstract}

Key words: Dentistry; Anesthetic techniques; Oral surgery.

\section{INTRODUÇÃO}

A anestesia local é um dos artifícios mais utilizados e efetivos para o controle da dor em Odontologia. Os primeiros registros desse tipo de analgesia mostram o emprego de várias substâncias para a obtenção desse efeito, dentre elas eram utilizadas: vapores de ervas, mistura de substâncias contendo ópio, vapores de gases, éter, clorofórmio e ciclopropano. Gradualmente, de acordo com a evolução e melhoria das performances, essas drogas foram sendo substituídas. (PRADO ET AL, 2003; MALAMED, 2013; ANDRADE, 2014)

Por definição, Stanley Malamed (2013) caracteriza a anestesia local como perda da sensibilidade em uma área circunscrita do corpo causada pela depressão da excitação das terminações nervosas ou pela inibição do processo de condução dos nervos 
periféricos. Além disso, a anestesia local promove a perda de sensibilidade sem que haja inconsciência. (PRADO ET AL, 2003; MALAMED, 2013)

Seja o tratamento clínico ou cirúrgico, a terapia Odontológica sempre despertou o medo e a ansiedade em pacientes. Alguns destes possuem traumas preexistentes e outros não, contudo, essa experiência emocional desagradável justifica-se em virtude de um passado de controle de dor ineficiente e rudimentar. (PRADO ET AL, 2003; MALAMED, 2013)

Para a obtenção de uma anestesia segura, com profundidade e duração adequadas, o cirurgião-dentista deve ter conhecimento farmacológico dos anestésicos locais e dos vasoconstritores, assim como deter o conhecimento sobre as técnicas anestésicas e sobre características anatômicas. Ademais, outras habilidades e atitudes são exigidas do administrador, tal como a empatia para que além do conhecimento científico, também saiba empregar, por meio de um esforço consciente, uma técnica anestésica menos dolorosa e traumática. Além disso, o profissional deve selecionar o correto equipamento para o bloqueio escolhido como agulhas de tamanho e calibre, evitando assim possíveis complicações e uma maior taxa de sucesso na realização da técnica. (ANDRADE, 2014; MALAMED, 2013; ANDRADE, 2014)

\section{REVISÃO DA LITERATURA}

REVISTA FLUMINENSE DE ODONTOLOGIA - ANO XXVII - N 55 - Janeiro / Julho 2021 
Tabela 1: Descrição dos cuidados e das regiões anestesiadas na realização das técnicas anestésicas.

\begin{tabular}{|c|c|c|c|c|c|c|c|c|}
\hline $\begin{array}{l}\text { Técnicas } \\
\text { anestésicas }\end{array}$ & Nervos anestesiados & $\begin{array}{c}\text { Área anestesiada: Tecidos } \\
\text { moles/duros e dentes } \\
\text { anestesiados }\end{array}$ & $\begin{array}{l}\text { Volume } \\
\text { mínimo de } \\
\text { anestésico }\end{array}$ & $\begin{array}{c}\text { Agulha } \\
\text { indicada }\end{array}$ & $\begin{array}{c}\text { \% de } \\
\text { aspiraçãa } \\
\text { positiva }\end{array}$ & $\begin{array}{l}\text { Profundidade de } \\
\text { penetração da } \\
\text { agulha }\end{array}$ & Pontos de referência & Possíveis complicações \\
\hline $\begin{array}{l}\text { Bloqueio do Nervo } \\
\text { Alveolar } \\
\text { Superoposterior }{ }^{1}\end{array}$ & $\begin{array}{l}\text {-Alveolar superior posterior e } \\
\text { seus ramos terminais. }\end{array}$ & $\begin{array}{l}\text {-Polpa, tecido periodontal, osso e } \\
\text { periósteo do terceiro, segundo e } \\
\text { primeiro molares superiores(raízes } \\
\text { palatina e disto- vestibular). }\end{array}$ & $\begin{array}{l}\bullet 0,9-1,8 \mathrm{ml} \\
* 1 \quad \text { tubete } \\
\text { possui } 1,8 \mathrm{ml}\end{array}$ & $\begin{array}{l}\text { - Agulha } \\
\text { curta de } \\
\text { calibre } 27 \\
\left(^{*}\right) \text { No Brasil } \\
\text { encontra-se } \\
\text { somente } \\
\text { curta de } \\
\text { calibre } 30 ;\end{array}$ & $\begin{array}{l}\text {-Aproximada } \\
\text { mente } 3,1 \%\end{array}$ & $\begin{array}{l}\text { - Em adultos: } \\
\text { aproximadamen } \\
\text { te profundidade } \\
\text { de } 16 \mathrm{~mm} \text {; } \\
\text { - Em crianças e } \\
\text { adultos } \\
\text { pequenos: } \\
\text { aproximadamen } \\
\text { te profundidade } \\
\text { de } 10 \text { a } 14 \mathrm{~mm} \text {. }\end{array}$ & $\begin{array}{l}\text {-Prega mucovestibular. } \\
\text { - Tuberosidade da maxila. } \\
\text {-Processo zigomático da } \\
\text { maxila. } \\
\text { - Local de penetração: prega } \\
\text { mucovestibular acima do } \\
\text { segundo molar superior. }\end{array}$ & $\begin{array}{l}\text { - Hematoma:agulhai ntroduzida } \\
\text { posteriormente ao plexc } \\
\text { venoso pterigoideo. Podendo } \\
\text { haver perfuração da artéria } \\
\text { maxilar (uso agulha curta } \\
\text { reduz o risco). } \\
\text {-Anestesia mandibular } \\
\text { Devido à localização } \\
\text { lateralmente ao nervo alveola } \\
\text { superior posterior. }\end{array}$ \\
\hline $\begin{array}{l}\text { Bloqueio do Nervo } \\
\text { Alveolar Superior } \\
\text { Médio (ASM) }\end{array}$ & $\begin{array}{l}\text {-Alveolar superior médio e seus } \\
\text { ramos terminais. }\end{array}$ & $\begin{array}{l}\text { - Polpa, tecido periodontal, osso e } \\
\text { periósteodo primeiro e segundo } \\
\text { pré-molares superiores, raiz } \\
\text { mesiovestibular do primeiro molar } \\
\text { superior. }\end{array}$ & $\begin{array}{lr}\bullet 0,9-1,2 \mathrm{ml} \\
* 1 & \text { tubete } \\
\text { possui } 1,8 \mathrm{ml}\end{array}$ & $\begin{array}{l}\text { - Agulha } \\
\text { curta ou } \\
\text { longa de } \\
\text { calibre } 27 \\
\text { (*)No Brasil }^{*} \text { encontra-se } \\
\text { somente de } \\
\text { curta de } \\
\text { calibre } 30 \text { e } \\
\text { longa de } \\
\text { calibre 27; } \\
\end{array}$ & $\begin{array}{l}\text { - Desprezível } \\
(<3 \%)\end{array}$ & $\begin{array}{l}\text { - Em adultos: } \\
\text { aproximadamen } \\
\text { te profundidade } \\
\text { de } 16 \mathrm{~mm} \text {; }\end{array}$ & $\begin{array}{l}\text { - Local de penetração: prega } \\
\text { mucovestibular acima do } \\
\text { segundo pré-molar superior. }\end{array}$ & $\begin{array}{l}\text {-Um hematoma pode se } \\
\text { desenvolver no local da } \\
\text { injeção. Deve-se aplica } \\
\text { pressão com gaze estéri } \\
\text { acima da lesão por } 60 \\
\text { segundos. }\end{array}$ \\
\hline $\begin{array}{l}\text { Bloqueio do Nervo } \\
\text { Infraorbitário (Nervo } \\
\text { Alveolar } \\
\text { Superoanterior }\end{array}$ & $\begin{array}{l}\text {-Alveolar superior anterior; } \\
\text {-Alveolar superior médio; } \\
\text {-Nervo infraorbitário; } \\
\text { a. Palpebral inferior; } \\
\text { b. Nasal lateral; } \\
\text { c. Labial superior. }\end{array}$ & $\begin{array}{l}\text {-Polpas do incisivo central } \\
\text { superior até o canino superior do } \\
\text { lado da injeção. } \\
\text {-Em cerca de } 72 \% \text { dos pacientes, } \\
\text { as polpas dos pré-molares } \\
\text { superiores e a raiz } \\
\text { mesiovestibular do primeiro molar. } \\
\text {-Periodonto vestibular (labial) e } \\
\text { osso destes mesmos dentes; } \\
\text { Pálpebra inferior, aspecto lateral } \\
\text { do nariz, lábio superior. }\end{array}$ & $\begin{array}{lr}\bullet 0,9-1,2 \mathrm{ml} \\
* 1 \quad \text { tubete } \\
\text { possui } 1,8 \mathrm{ml}\end{array}$ & $\begin{array}{l}- \text { Agulha } \\
\text { longa de } \\
\text { calibre } 25 \\
\text { ou } 27 \\
\text { (*)No Brasil }^{*} \text { encontra-se } \\
\text { somente } \\
\text { longa de } \\
\text { calibre 27; }\end{array}$ & $\begin{array}{l}\text {-Aproximada } \\
\text { mente } 0,7 \%\end{array}$ & $\begin{array}{l}\text { - Em adultos: } \\
\text { aproximadamen } \\
\text { te profundidade } \\
\text { de } 16 \mathrm{~mm} \text {; }\end{array}$ & $\begin{array}{l}\text { - Prega mucovestibular; } \\
\text { - Incisura infraorbitária; } \\
\text {-Forame infraorbitário; } \\
\text { - Local de penetração: prega } \\
\text { mucovestibular sobre o primeiro } \\
\text { pré-molar. }\end{array}$ & $\begin{array}{l}\text {-Um hematoma pode se } \\
\text { formar (raramente) napálpebra } \\
\text { inferior e nos tecidos entre } \\
\text { esta e o forame infraorbitário } \\
\text { Para resolver isso, aplica } \\
\text { pressão nos tecidos moles } \\
\text { acima do forame por } 2 \text { a } \\
\text { minutos; }\end{array}$ \\
\hline $\begin{array}{l}\text { Bloqueio do Nervo } \\
\text { Palatino Maior }\end{array}$ & - Palatino maior; & $\begin{array}{l}\text {-A parte posterior do palato duro } \\
\text { e os tecidos moles sobrejacentes, } \\
\text { anteriormente até o primeiropré- } \\
\text { molar e medialmente até a linha } \\
\text { média. }\end{array}$ & $\begin{array}{l}\qquad 0,45-0,6 \\
\text { ml } \\
\text { *1 tubete } \\
\text { possui } 1,8 \mathrm{ml}\end{array}$ & $\begin{array}{l}\text {-Agulha } \\
\text { curta } \\
\text { calibre } 27 \\
\left(^{*}\right) \text { No Brasil } \\
\text { encontra-se }\end{array}$ & $\begin{array}{l}\bullet \text { Menos } \\
1 \%\end{array}$ & $\begin{array}{l}\text {-Aproximadame } \\
\text { nte de } 5 \mathrm{~mm} \text {; }\end{array}$ & $\begin{array}{l}\text { - Forame palatino maior e } \\
\text { junção do processo alveolar } \\
\text { maxilar e osso palatino; } \\
\text { - Local de penetração: } 1 \text { a } 2 \\
\text { mm }\end{array}$ & $\begin{array}{l}\text { - Isquemia e necrose dos } \\
\text { tecidos moles, quando uma } \\
\text { solução vasoconstritora muitc } \\
\text { concentrada é utilizada em } \\
\text { grande volume; Nunca utiliza }\end{array}$ \\
\hline
\end{tabular}




\begin{tabular}{|c|c|c|c|c|c|c|c|c|}
\hline & & & & $\begin{array}{l}\text { somente } \\
\text { curta de } \\
\text { calibre 30; }\end{array}$ & & & $\begin{array}{l}\text { anterior ao forame palatino } \\
\text { maior. }\end{array}$ & $\begin{array}{l}\text { noradrenalina para hemostasia } \\
\text { desta região; } \\
\text { •Hematoma é possível, mas é } \\
\text { raro devido à densidade e à } \\
\text { firme aderência dos tecidos } \\
\text { palatinos ao osso subjacente; } \\
\text {-O palato mole pode } \\
\text { seranestesiado. Isto é possível } \\
\text { nos casos em que o nervo } \\
\text { palatino médio está próximo } \\
\text { ao local da injeção. }\end{array}$ \\
\hline $\begin{array}{l}\text { Bloqueio do Nervo } \\
\text { Nasopalatino }\end{array}$ & $\begin{array}{l}\text { •Nervos nasopalatinos } \\
\text { bilateralmente. }\end{array}$ & $\begin{array}{l}\text { - Porção anterior do palato duro } \\
\text { (tecidos moles e duros) } \\
\text { bilateralmente desde a face mesial } \\
\text { do primeiro pré-molar direito à face } \\
\text { mesial do primeiro pré-molar } \\
\text { esquerdo. }\end{array}$ & $\begin{array}{l}\bullet 0,45 \quad \mathrm{ml} \\
\text { (máximo) } \\
* 1 \quad \text { tubete } \\
\text { possui } 1,8 \mathrm{ml}\end{array}$ & $\begin{array}{l}\text {-Agulha } \\
\text { curta de } \\
\text { calibre } 27 \\
\left({ }^{*}\right) \text { No Brasil } \\
\text { encontra-se } \\
\text { somente de } \\
\text { curta de } \\
\text { calibre } 30 ;\end{array}$ & -Menos de $1 \%$ & $\begin{array}{l}\text {-Aproximadame } \\
\text { nte } 5 \mathrm{~mm} \text {; }\end{array}$ & $\begin{array}{l}\text { - Incisivos centrais e papila } \\
\text { incisiva; } \\
\text { - Local de penetração: mucosa } \\
\text { palatina imediatamente lateralà } \\
\text { papila incisiva (localizada na } \\
\text { linha média atrás dos incisivos } \\
\text { centrais). }\end{array}$ & $\begin{array}{l}\text { - Isquemia e necrose dos } \\
\text { tecidos moles, quando uma } \\
\text { solução vasoconstritora muito } \\
\text { concentrada é utilizada em } \\
\text { grande volume; Nunca utilizar } \\
\text { noradrenalina para hemostasia } \\
\text { desta região; } \\
\text { - Hematoma é possível, mas é } \\
\text { raro devido à densidade e à } \\
\text { firme aderência dos tecidos } \\
\text { palatinos ao osso subjacente. }\end{array}$ \\
\hline $\begin{array}{l}\text { Bloqueio do Nervo } \\
\text { Maxilar } \\
\text { (Tuberosidade Alta) }\end{array}$ & $\begin{array}{llll}\text {-Divisão maxilar do nervo } \\
\text { trigêmeo. }\end{array}$ & $\begin{array}{l}\text {-Anestesia pulpar dos dentes } \\
\text { superiores no lado do bloqueio; } \\
\text {-Periodonto vestibular e osso } \\
\text { sobrejacente a estes dentes; } \\
\text { - Tecidos moles e osso do palato } \\
\text { duro e parte do palato } \\
\text { mole,medialmente à linha média; } \\
\text { - Pele da pálpebra inferior, lateral } \\
\text { do nariz, bochecha e lábiosuperior; }\end{array}$ & \begin{tabular}{|r}
$\bullet 0,9-1,2 \mathrm{ml}$ \\
$* 1 \quad$ tubete \\
possui $1,8 \mathrm{ml}$
\end{tabular} & $\begin{array}{l}\text {-Agulha } \\
\text { curta de } \\
\text { calibre } 27 \\
\text { ou } 25 \\
\left(^{*}\right) \text { No Brasil } \\
\text { encontra-se } \\
\text { somente } \\
\text { curta de } \\
\text { calibre } 30 ;\end{array}$ & $\begin{array}{l}\text {-Menor que } \\
1 \%\end{array}$ & $\begin{array}{l}\text {-Aproximadame } \\
\text { nte } 5 \mathrm{~mm} \text {; }\end{array}$ & $\begin{array}{l}\text { - Prega mucovestibular na face } \\
\text { distal do do segundo } \\
\text { molarsuperior; } \\
\text { - Tuberosidade da maxila; } \\
\text { - Processo zigomático da } \\
\text { maxila; } \\
\text { - Área de penetração: altura da } \\
\text { prega mucovestibular acima da } \\
\text { face distal do segundo molar } \\
\text { superior. }\end{array}$ & $\begin{array}{l}\text { - Hematoma se desenvolve } \\
\text { rapidamente } \\
\text { artériamaxilar for puncionada } \\
\text { durante o bloqueio. }\end{array}$ \\
\hline $\begin{array}{l}\text { Bloqueio Do Nervo } \\
\text { Alveolar Inferior }\end{array}$ & $\begin{array}{l}\text { - Alveolar inferior, um ramo da } \\
\text { divisão posterior da divisão } \\
\text { mandibular do nervo trigêmeo } \\
\text { (V3); } \\
\text { - Incisivo; } \\
\text { - Mentual; } \\
\text { - Lingual (comumente). }\end{array}$ & $\begin{array}{l}\text { - Dentes mandibulares até a linha } \\
\text { média; } \\
\text {-Corpo da mandíbula, parte } \\
\text { inferior do ramo da mandíbula; } \\
\text {-Mucoperiósteo bucal, membrana } \\
\text { mucosa anteriormente ao forame } \\
\text { mentual (nervo mentual); } \\
\text {-Dois terços anteriores da língua e } \\
\text { assoalho da cavidade oral(nervo } \\
\text { lingual); } \\
\text {-Periósteo e tecidos moles } \\
\text { linguais (nervo lingual); }\end{array}$ & $\begin{array}{lr}\bullet 1,5 \mathrm{ml} \\
\text { *1 } \quad \text { tubete } \\
\text { possui } 1,8 \mathrm{ml}\end{array}$ & $\begin{array}{l}\text { - Agulha } \\
\text { longa de } \\
\text { calibre 25 } \\
\left(^{*}\right) \text { No Brasil } \\
\text { encontra-se } \\
\text { somente } \\
\text { longa de } \\
\text { calibre 27; }\end{array}$ & • $10 \%$ a $15 \%$ & $\begin{array}{l}- \text { Aproximadame } \\
\text { nte de } 20 \text { a } 25 \\
\text { mm; }\end{array}$ & $\begin{array}{l}\text { - Incisura coronoide } \\
\text { (concavidade maior na } \\
\text { bordaanterior do ramo da } \\
\text { mandíbula); } \\
\text { - Rafe pterigomandibular (parte } \\
\text { vertical); } \\
\text {-Plano oclusal dos dentes } \\
\text { mandibulares posteriores; } \\
\text { - Área de penetração: } \\
\text { membrana mucosa do lado } \\
\text { medial(lingual) do ramo da } \\
\text { mandíbula, na interseção de } \\
\text { duaslinhas - uma horizontal, }\end{array}$ & $\begin{array}{l}\text { - Hematoma; } \\
\text { - Trismo; } \\
\text {-Paralisia facial transitória } \\
\text { (anestesia do nervo facial): } \\
\text { produzida pelo depósito do } \\
\text { anestésico local no corpo da } \\
\text { glândula parótida. }\end{array}$ \\
\hline
\end{tabular}

REVISTA FLUMINENSE DE ODONTOLOGIA - ANO XXVII - N 55 - Janeiro / Julho 2021 


\begin{tabular}{|c|c|c|c|c|c|c|c|c|}
\hline & & & & & & & $\begin{array}{l}\text { representando a altura } \\
\text { deinserção da agulha, e a outra } \\
\text { vertical, representando }{ }^{\circ} \\
\text { planoanteroposterior de injeção. }\end{array}$ & \\
\hline $\begin{array}{l}\text { Bloqueio Do Nervo } \\
\text { Bucal }\end{array}$ & $\begin{array}{l}\text { - Bucal (um ramo da divisão } \\
\text { anteriorde V3). }\end{array}$ & $\begin{array}{l}\text {-Tecidos moles e periósteo bucal } \\
\text { dos dentesmolares mandibulares; }\end{array}$ & $\begin{array}{l}\bullet 0,3 \mathrm{ml} ; \\
\text { *1 } \quad \text { tubete } \\
\text { possui } 1,8 \mathrm{ml}\end{array}$ & $\begin{array}{l}\text { - Agulha } \\
\text { longa de } \\
\text { calibre } 25 \\
\text { ou 27; } \\
\left(^{*}\right) \text { No Brasil } \\
\text { encontra-se } \\
\text { somente de } \\
\text { longa de } \\
\text { calibre 27; }\end{array}$ & $\bullet 0,7 \%$ & $\begin{array}{l}\text {-Aproximadame } \\
\text { nte de } 2 \text { a } 4 \\
\mathrm{~mm}\end{array}$ & $\begin{array}{l}\text { - Molares mandibulares, prega } \\
\text { mucobucal; } \\
\text { - Área de penetração: } \\
\text { membrana mucosa distal e } \\
\text { bucal do segundo pré-molar. }\end{array}$ & $\begin{array}{l}\text { - Hematoma } \\
\text { pressãocom gaze diretamente } \\
\text { à área do sangramento pelo } \\
\text { período mínimo de } 3 \text { a } 5 \\
\text { minutos. }\end{array}$ \\
\hline $\begin{array}{l}\text { Bloqueio Do Nervo } \\
\text { Mandibular: } \quad \text { A } \\
\text { Técnica De Gow- } \\
\text { Gates }\end{array}$ & $\begin{array}{l}\text {-Alveolar inferior; } \\
\text {-Mentual; } \\
\text {-Incisivo; } \\
\text {-Lingual; } \\
\text {-Milo-hióideo; } \\
\text {-Auriculotemporal; } \\
\text {-Bucal (em } 75 \% \text { dos pacientes). }\end{array}$ & $\begin{array}{l}\text { - Dentes mandibulares até a linha } \\
\text { média; } \\
\text {-Mucoperiósteo e membranas } \\
\text { mucosas bucais do ladoda } \\
\text { injeção; } \\
\text { - Dois terços anteriores da língua } \\
\text { e assoalho da cavidade oral; } \\
\text {-Tecidos moles e periósteo da } \\
\text { língua; } \\
\text {-Corpo da mandíbula, parte } \\
\text { inferior do ramo da mandibula; } \\
\text {-Pele sobre o zigoma, parte } \\
\text { posterior da bochecha e } \\
\text { regiõestemporais. }\end{array}$ & $\begin{array}{l}\bullet 1,8-3,0 \mathrm{ml} ; \\
* 1 \quad \text { tubete } \\
\text { possui } 1,8 \mathrm{ml}\end{array}$ & $\begin{array}{l}\text { - Agulha } \\
\text { longa de } \\
\text { calibre } 25 \\
\text { ou } 27 ; \\
\left(^{*}\right) \text { No Brasil } \\
\text { encontra-se } \\
\text { somente de } \\
\text { longa de } \\
\text { calibre 27; }\end{array}$ & - $2 \%$ & $\begin{array}{l}\text {-Aproximadame } \\
\text { nte de } 25 \mathrm{~mm} \text {; }\end{array}$ & $\begin{array}{l}\text { - Extraorais: - borda inferior do } \\
\text { trago (incisura intertrágica); } \\
\text { - Canto da boca; } \\
\text {-Intraorais: - altura da injeção } \\
\text { estabelecida pela colocaçãoda } \\
\text { ponta da agulha logo abaixo da } \\
\text { cúspidemesiolingual } \\
\text { (mesiopalatina) do segundo } \\
\text { molar maxilar; } \\
\text {-Penetração dos tecidos moles } \\
\text { num ponto imediatamente distal } \\
\text { ao segundo molar maxilarcomo } \\
\text { a altura estabelecida na etapa } \\
\text { precedente; } \\
\text {-Área de penetração: } \\
\text { membrana mucosa na parte } \\
\text { mesial doramo da mandíbula, } \\
\text { numa linha da incisura } \\
\text { intertrágica até o canto da boca, } \\
\text { imediatamente distal ao ao } \\
\text { segundo molarmaxilar. }\end{array}$ & $\begin{array}{l}\text { - Hematoma; } \\
\text {-Trismo; } \\
\text { - Paralisia temporária do III, IV } \\
\text { e VI nervos cranianos. }\end{array}$ \\
\hline $\begin{array}{l}\text { Bloqueio } \\
\text { Mandibular De Boca } \\
\text { Fechada } \\
\text { De Vazirani-Akinosi }\end{array}$ & $\begin{array}{l}\text {-Alveolar inferior; } \\
\text {-Incisivo; } \\
\text {-Mentual; } \\
\text { - Lingual; } \\
\text {-Milo-hióideo. }\end{array}$ & $\begin{array}{l}\text { - Dentes mandibulares até a linha } \\
\text { média; } \\
\text { - Corpo da mandíbula e parte } \\
\text { inferior do ramo mandibular; } \\
\text {-Mucoperiósteo e membrana } \\
\text { mucosa bucais anteriores } \\
\text { aoforame mentual; } \\
\text { - Dois terços anteriores da língua } \\
\text { e assoalho da cavidade oral(nervo } \\
\text { lingual); } \\
\text { - Tecidos moles e periósteo } \\
\text { linguais (nervo lingual). }\end{array}$ & $\mid \begin{array}{lr}\bullet 1,5-1,8 \mathrm{ml} \\
* 1 & \text { tubete } \\
\text { possui } 1,8 \mathrm{ml}\end{array}$ & $\begin{array}{l}\text { - Agulha } \\
\text { longa de } \\
\text { calibre 25; } \\
\left(^{*}\right) \text { No Brasil } \\
\text { encontra-se } \\
\text { somente } \\
\text { longa de } \\
\text { calibre 27; }\end{array}$ & $\bullet<10 \%$ & $\begin{array}{l}\text { - Em adultos: } \\
\text { aproximadamen } \\
\text { te } 25 \mathrm{~mm} \text {; }\end{array}$ & $\begin{array}{l}\text { - Junção mucogengival do } \\
\text { terceiro (ou do segundo) } \\
\text { molarmaxilar; } \\
\text { - Tuberosidade maxilar; } \\
\text { - Incisura coronoide no ramo da } \\
\text { mandíbula; } \\
\text { - Área de penetração: tecidos } \\
\text { moles sobrejacentes à borda } \\
\text { medial (lingual) do ramo } \\
\text { mandibular diretamente } \\
\text { adjacente à tuberosidade } \\
\text { maxilar, na parte alta de junção }\end{array}$ & $\begin{array}{l}\text { - Hematoma; } \\
\text {-Trismo; } \\
\text { - Paralisia transitória do nervo } \\
\text { facial (VII): essa paralisia é } \\
\text { causada pela inserção } \\
\text { excessiva e ainjeção da } \\
\text { solução anestésica local no } \\
\text { corpo da glândulaparótida. }\end{array}$ \\
\hline
\end{tabular}




\begin{tabular}{|c|c|c|c|c|c|c|c|c|}
\hline & & & & & & & $\begin{array}{l}\text { mucogengival circunvizinha ao } \\
\text { terceiro molar maxilar. }\end{array}$ & \\
\hline $\begin{array}{l}\text { Bloqueio Do Nervo } \\
\text { Mentual }\end{array}$ & $\begin{array}{l}\text { - Mentual, um ramo terminal do } \\
\text { alveolar inferior. }\end{array}$ & $\begin{array}{l}\text {-Membrana mucosa bucal, } \\
\text { anteriormente ao forame mentual } \\
\text { (em torno do segundo pré-molar) } \\
\text { até a linhamédia e a pele do lábio } \\
\text { inferior e do queixo. }\end{array}$ & $\begin{array}{l}\bullet 0,6 \mathrm{ml} \\
\text { *1 tubete } \\
\text { possui 1,8 ml }\end{array}$ & $\begin{array}{l}\text {-Agulha } \\
\text { curta de } \\
\text { calibre } 25 \\
\text { ou 27; } \\
\text { (*)No Brasil }^{*} \text { encontra-se } \\
\text { somente de } \\
\text { curta de } \\
\text { calibre 30; }\end{array}$ & $\bullet 5,7 \%$ & $\begin{array}{l}\text {-Aproximadame } \\
\text { nte } 5 \text { a } 6 \mathrm{~mm} \text {; }\end{array}$ & $\begin{array}{l}\text {-Pré-molares mandibulares e } \\
\text { prega mucobucal; } \\
\text { - Área de penetração: prega } \\
\text { mucobucal no forame mentual } \\
\text { ouimediatamente anterior ao } \\
\text { mesmo. }\end{array}$ & $\begin{array}{l}\text {-Hematoma; } \\
\text {-Parestesias no lábio e/ou } \\
\text { queixo, devido o contato da } \\
\text { agulha como nervo mentual. }\end{array}$ \\
\hline $\begin{array}{l}\text { Bloqueio Do Nervo } \\
\text { Incisivo }\end{array}$ & •Mentual e incisivo. & $\begin{array}{l}\text {-Membrana mucosa bucal anterior } \\
\text { ao forame mentual, geralmente do } \\
\text { segundo pré-molar até a linha } \\
\text { média; } \\
\text { - Lábio inferior e pele do queixo; } \\
\text {-Fibras nervosas pulpares aos } \\
\text { pré-molares, ao canino e } \\
\text { aosincisivos. }\end{array}$ & \begin{tabular}{|l}
$\bullet 0,6-0,9 \mathrm{ml} ;$ \\
*1 $\quad$ tubete \\
possui $1,8 \mathrm{ml}$
\end{tabular} & $\begin{array}{l}\text {-Agulha } \\
\text { curta de } \\
\text { calibre 27; } \\
\left(^{*}\right) \text { No Brasil } \\
\text { encontra-se } \\
\text { somente } \\
\text { curta de } \\
\text { calibre 30; }\end{array}$ & $\bullet 5,7 \%$ & $\begin{array}{l}\text {-Aproximadame } \\
\text { nte } 5 \text { a } 6 \mathrm{~mm} \text {; }\end{array}$ & $\begin{array}{l}\text { - Pré-molares mandibulares e } \\
\text { prega mucobucal; } \\
\text { - Área de penetração: prega } \\
\text { mucobucal no forame mentual } \\
\text { ouimediatamente anterior ao } \\
\text { mesmo (área alvo: saída do } \\
\text { forame mentual e seu interior, } \\
\text { onde o n. incisivo se encontra). }\end{array}$ & $\begin{array}{l}\text {-Hematoma; } \\
\text {-Parestesias no lábio e/ou } \\
\text { queixo, devido o contato da } \\
\text { agulha como nervo mentual. }\end{array}$ \\
\hline
\end{tabular}




\section{CONCLUSÃO}

Diante da expectativa do paciente, comumente negativa, do atendimento odontológico devido à ansiedade, medo e até mesmo ao trauma, é fundamental que o cirurgião-dentista tenha conhecimento de todas as técnicas. Sobretudo, ter também atenção quanto à profundidade de penetração da agulha, bem como, à pontos de referência e possíveis complicações, a fim de reduzir a chance de falha e de tranquilizar o paciente.

\section{REFERÊNCIAS}

1. Malamed, S. F. Manual de Anestesia Local - Elsevier, 6a ed., 2013.

2. Prado, R. Cirurgia Bucomaxilofacial - Guanabara Koogan, 2004.

3.Andrade, E. D. Terapêutica Medicamentosa em Odontologia - Artes Médicas, 3a ed., 2014. 